\title{
Learning with dogs: Human-animal bonds and understandings of relationships and reflexivity in practitioner-research
}

Nerilee Ceatha, SPHeRE PhD scholar with the School of Social Policy, Social Work and Social Justice, University College Dublin

\begin{abstract}
INTRODUCTION: This article highlights the importance of ethnographic observations of human-animal bonds (HAB) to inform social work practice and applied social research. It explores the relationship between the author and Bruno, a rescue dog, through conventional ideas on attachment theory, connectedness and containment.

METHODS: These perspectives are applied to the author's experiences of undertaking a $\mathrm{PhD}$ on the protective factors that promote LGBTI+ youth wellbeing. This emphasises reflexivity as an integral component of practitioner research, with the potential to explore the complexities and subjectivities of our emotional lives.

FINDINGS: Through recognition of the dynamics of attachment, our roles as companion-carers prompt help-seeking to ensure reflective practice and effective caregiving. Our relationships with companion-animals resonate with the process of undertaking a $\mathrm{PhD}$, through prioritising self-care and seeking work-life balance. These ideas are also relevant for collaborative studies underpinned by an iterative research process, described by a Consulting, Conducting, Collaborating and Checking cycle.
\end{abstract}

CONCLUSION: The article concludes with an appeal to social work practitioners and practitionerresearchers to discover ways in which concepts of $\mathrm{HAB}$, and our interconnectedness with all living beings, can be applied to policy, practice and research with those whom we work with, their families and within our broader communities.

KEYWORDS: Human-animal bonds; reflexivity; subjectivity; ethnographic observation; LGBTI+ youth

"A dog can never tell you what she knows from the smells of the world, but you know, watching her, that you know almost nothing." (Mary Oliver, Dog Songs)

\section{Introduction}

Bruno came into my life two months into my $\mathrm{PhD}$, a mixed-methods, participatory study on the protective factors that promote LGBTI+ youth wellbeing. Core to the project is the intention to engage in research that promotes "learning with" LGBTI+ communities (Baker \& Beagan, 2014). This account explains the development of a human-animal bond with Bruno, a rescue dog. This has enabled me to hypothesise how my $\mathrm{PhD}$ studies, and my relationship with
AOTEAROA

NEW ZEALAND SOCIAL WORK 32(4), 77-83.

CORRESPONDENCE TO: Nerilee Ceatha nerilee.ceatha@ ucdconnect.ie 
Bruno, can help develop understandings of practitioner and researcher subjectivity, enhance the use of self within relationships and recognise our interconnection with all living beings (Hanrahan, 2011; Siegel, 2020).

\section{Meeting Bruno}

Bruno, a terrier cross, arrived at Dog's Trust, aged 8+, after his carer died, losing everything familiar: his companion, home, routine, neighbourhood - raising the issue of grieving (Hayes, 2017). It further transpired he had untreated pain with spondylosis, a degenerative disease of the disks, and advanced arthritis. Once his pain was managed, the Dog's Trust attempted to rehome Bruno for 31/2 years; he featured in their "Underdogs" campaign, with a television advertisement and book chapter (Hayes, 2017). With no knowledge of his background, on my first visit I looked deeply into Bruno's eyes and immediately felt connected. The suggestion that holding a dog's gaze prompts the release of oxytocin may explain this (Horowitz, 2010). So began the visits with an anxious Bruno pacing the perimeter of the room, only seeking contact for treats. On the 16th visit he finally sat down, licking his paws, a form of selfsoothing, coming closer for a pat. Four home visits later, Bruno came on an overnight, and stayed, becoming an integral part of family and home life. The next sections suggest a range of theories which might explain these experiences.

\section{Human-animal bonds and attachment theory}

My experiences with Bruno prompted further exploration of the phenomenon of human-animal bonds (HAB) and their mutual benefits (Walsh, 2009). While there is no consensus on a definition, Russow (2002) highlighted that such bonds: 1 . involve a relationship between a human and non-human animal; 2 . are reciprocal; and 3. promote increased wellbeing for both (Walsh, 2009). Three primary theoretical frameworks have been used to develop these ideas: biophilia; social mediation; and attachment theory (Phillips \& Hazleby, 2018). Such ideas are not all new, for example, Bowlby's ground-breaking work on attachment was influenced by animal observations. He noted that, when frightened, some animals, including humans, seek protection from an adult (Sroufe \& Siegel, 2011). While broader notions of wellbeing are more demonstrable in terms of human need, companion animals can be important attachment figures (Walsh, 2009).

Drawing on my prior experiential learning on the Theory of Attachment Based Exploratory Interest Sharing (Heard, Lake, \& McClusky, 2012), my relationship with Bruno aligns with ideas from the animal welfare field. Such approaches critically analyse anthropocentric assumptions of ownership and humans as masters over 'their' animals (Walsh, 2009). Rather, a more balanced view is forwarded where humans and animals are regarded as companions (Hanrahan, 2011). My observation of Bruno's experience and development of our HAB through connection, a sense of compassion and containment are now discussed.

\section{Connection and compassion}

It has been suggested that human beings are "hardwired" for connection and the essential nature of relationships (Brown, 2015). The human predisposition to seek and give care extends to canines and other animals. Patterns of attachment can be observed through $\mathrm{HAB}$, with social interactions particularly important to dogs (Topál, et al., 2005). The Dog's Trust had recommended a hands-off approach with Bruno (Hayes, 2017, p. 228), however, he quickly sought closeness and affection through tippy-tappy paws, wagging tail, brushes, pats and belly rubs. While this provided a sense of mutual contentment, it made it difficult to realise when Bruno was triggered, presumably from past experiences. I can only speculate that triggers were associated with the time when his carer died, leaving Bruno alone. From an attachment perspective, his apparent separation 
anxiety was understandable (Hayes, 2017). I observed Bruno's fear of abandonment where he tended to lie in the hall, across the doorway, apparently to prevent anyone leaving. One way of addressing this was the use of cues, for example, by offering a high-value treat when leaving to create a sense of expectation, reinforcing his expertise. Bruno now anticipates my return, with reunions joyous and reassuring, tail wagging madly, as he investigates the smells of the world on my shoes (Horowitz, 2010). The careseeking-caregiving attachment dynamic is goal-corrected; when the need for effective care is met, the needs of both careseeker and caregiver are assuaged (Heard et al., 2012; Siegel \& Bryson, 2020).

Walks with Bruno are all about sniffing as he explores his social world through his nose. Sniff-walks offer the potential to lower his pulse and have a calming effect (Horowitz, 2010). There were, however, reminders of the past that needed to be responded to compassionately. The vet confirmed that Bruno had experienced multiple painful, untreated ear infections, irreparably damaging his hearing, possibly explaining his tendency to remain on alert. Bruno had to decipher the meaning of coats and shoes: walk, with me? or leaving, without me? The Dog's Trust behavioural trainer provided support in providing clear visual cues, reinforcing his expertise.

Brown suggests "vulnerability is our greatest measure of courage" (2015, p. 3). "Learning with" Bruno necessitates a deep engagement with my own subjectivity, vulnerability and humanity. He has taught me that our vulnerabilities aren't limitations, can be strengths and provide creative possibilities. Sniff-walk adventures are unaffected by sirens, thunder or fireworks. A downpour is an opportunity for a blow-dry, without the high-pitched sound of the hairdryer.

\section{Containment}

Kvale and Brinkmann highlight the original Latin meaning of conversation as "wandering together with" - a journey with locals in their cultural setting where they share insights into their lived experience (2009, p. 48). It is suggested that companion animals understand and communicate through behaviour, providing insights into their inner world (Horowitz, 2010; Walsh, 2009). The Dog's Trust explained Bruno's history of biting, possibly linked to issues of pain. I had also observed Bruno's reaction to sticks, startling at a sweeping brush, walking stick or flag pole. It appeared he had learned not to growl; removing his valuable selfdefense system (Horowitz, 2010). It may be that Bruno expressed fear or pain through snapping, snarling or biting, particularly when triggered by objects.

Levine suggests that "trauma is not what happens to us, but what we hold inside in the absence of an empathetic witness" (2010, p. iv). Through observation and reflection with the behavioural trainer, I began "learning with" Bruno about attunement, mentalisation and how containment is an important mechanism in responding to trauma. On one occasion I tried to smooth the crumpled sheepskin beneath him, causing Bruno to snap. While I coaxed him back to bed, trying to soothe him, it was too soon. There was terror in his eyes, mirrored in mine, yet, to my surprise, and despite my nervousness, Bruno sought my proximity. On reflection, by acknowledging and containing my feelings, this supported Bruno to seek physical closeness and be soothed. All relationships experience ruptures; containment can facilitate repair (Levine, 2010).

\section{Bruno, me and my PhD study}

Ethnographic approaches, with their focus on observation of natural phenomena, are mainstream in applied social research (Brewer, 2000; Briggs, 2017; Cooper, 2017). However, Brewer (2000) cautions against the temptation to assume that observation somehow represents an objective reality. Rather, observation encourages awareness of subjective feelings and the ability to mentalise (Cooper, 2017), which may 
provoke powerful feelings and uncertainty (Briggs, 2017). In some ways this reflects my developing ideas and thinking around research and my PhD study; observations of HAB offer the potential to develop and deepen our understandings of our positionality.

Recognition of my subjectivity is integral to collaborative research with LGBTI+ youth. "Learning with" Bruno has strengthened my approach to conducting my study. Undertaking a PhD can be stressful; potentially undermining one's self-belief. My experience with Bruno offers mutual, reciprocal enrichment through our HAB. As such, by ensuring that he feels safe, seen and soothed (fundamental to secure attachment) our needs are assuaged (Horowitz, 2010; Siegel \& Bryson, 2020). Our companion-carer relationship is regularly discussed in $\mathrm{PhD}$ supervision, particularly in understanding self-care and creating work-life balance. Clinical social work supervision is underpinned by reflective practice on the careseekingcaregiving dynamic (Heard et al., 2012). My role as Bruno's carer-companion and as a novice-researcher, requires prioritisation of my own help-seeking. In attempting to meet Bruno's needs, my self-efficacy has been enhanced, reinforcing a sense of my own competence.
Maxwell's (2009) suggestion of memo writing is helpful as part of the process of reflexivity. This provides a template for a written record providing a brief description, analysis, and learning. Maintaining a reflexive journal and "learning with" Bruno has provided a parallel process informing my PhD and critical thinking on participation. It is only possible to connect with Bruno through an openness to my lack of expertise and recognition of his. This is mirrored in the PhD process with LGBTI+ youth conceptualised in Figure 1, below, as an iterative four-stage research cycle.

This cycle anticipates that LGBTI+ youth, when asked, will have many opinions on matters that affect them and have the ability to participate with interest, providing valuable insights (Ceatha, Bustillo, Tully, James, \& Crowley, 2020). The design assumes that the views and identity of the researcher will impact on the study, even in the process of promoting participation. However, "learning with" LGBTI+ youth highlights the potential contribution of ethnographic approaches in problematising binary emic and etic divides.

\section{“Learning with” LGBTI+ youth}

Levine (2010) highlights that all of those exposed to trauma are equally involved in
- Discuss, design and develop in consultation with LGBTI+ youth and communities
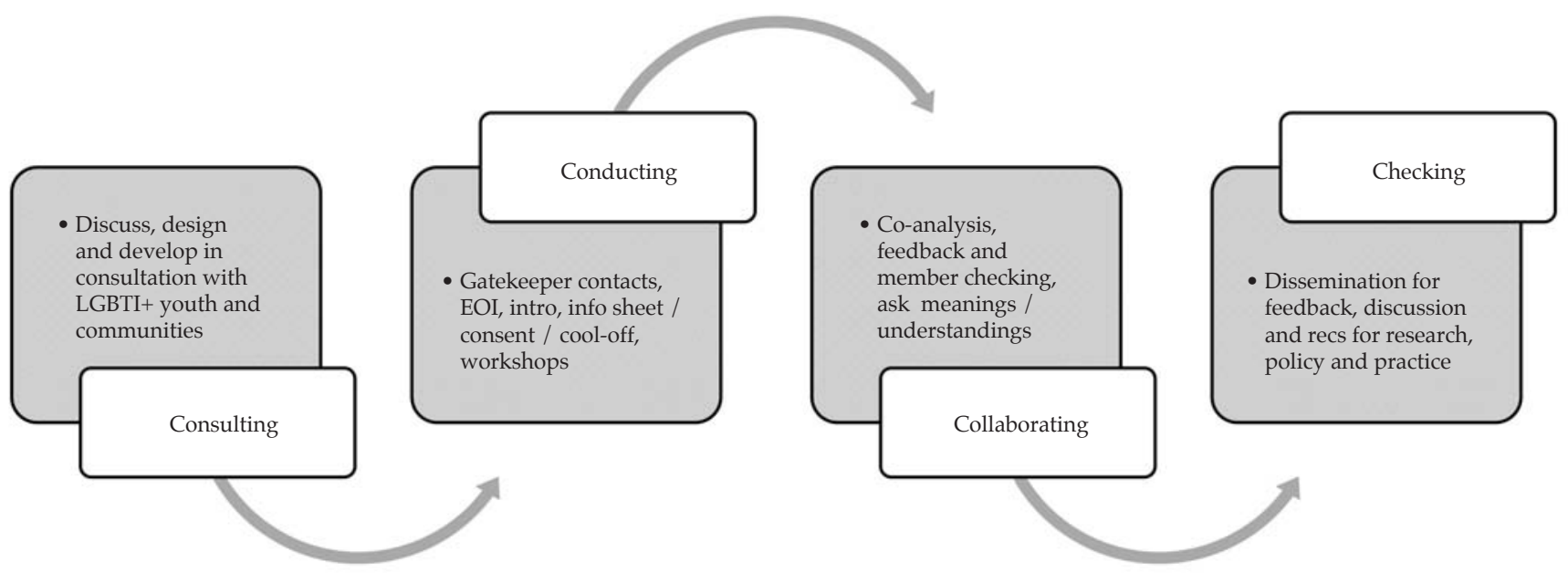

Figure 1. Promoting LGBTI+ youth involvement in research processes. 
their own wellbeing, emphasising the ways in which trauma and healing are experienced collectively. While I know some of Bruno's history, such narratives can be both limited and limiting (Siegel, 2020). This has a parallel with my PhD study which seeks to problematise deficit-focused narratives, representing LGBTI+ communities solely in relation to vulnerability (Ceatha, 2016).

LaSala (2003) suggests that ethnographic methodologies are particularly beneficial in researching LGBTI+ communities, generating emic insights of cultural insiders' self-understandings, alongside etic research perspectives. The emic approach favours the research participants' words, views and experience-giving weight to insider perspectives from the bottom up. In contrast, the etic approach uses theories, concepts and ideas as a starting point-providing an outsider perspective from the top down. Through my PhD study, I am seeking to problematise the binary nature of emic and etic divisions. Rather, I wish to privilege LGBTI+ youth knowledge and knowing, underpinned by a fundamental belief in their emic and etic expertise by experience (Ceatha et al., 2020). Consistent with transformative mixed-methods paradigms, these approaches are motivated by child-centred and rightsbased beliefs (Mertens \& Ginsberg, 2008).

Baker and Beagan (2014) suggested that promoting participation demands culturally competent practice underpinned by values of social justice, equity and valuing diversity. While cultural competence is contested, they underscore the importance of "learning with" LGBTI+ communities. As a cultural insider, fully immersed within LGBTI+ communities, acknowledging my subjectivity is integral to this process, including my insider status ( $\mathrm{La}$ Sala, 2003). This requires ongoing evaluation of the beliefs and assumptions underpinning the study and actively seeking feedback in order to continuously interrogate my frame of reference (Cooper, 2017; Maxwell, 2009). Seeking input from within LGBTI+ communities brings a reflexive approach to my own positionality; integral to researcher accountability. This recognises the social and cultural capital embedded within LGBTI+ networks (Ceatha, Mayock, Campbell, Noone, \& Browne, 2019). It is of particular importance in light of suggestions that social workers may struggle to engage around sexuality, limiting their engagement in reflexively informed practice (Schaub, Willis, \& Dunk-West, 2017).

\section{Implications for research, policy and practice}

This paper has argued for need to problematise binary anthropocentric constructs which reinscribe the humananimal divide. By attending to our relations with all living beings and "learning with" companion animals, we can become better social workers, practitioner-researchers and human beings. A core aspect of this process of betterment is reflexivity about both research processes and our participants, vis-à-vis our positionality. Ethnographic observation can evoke powerful responses, including uncertainty (Briggs, 2017). This also applies to observation of $\mathrm{HAB}$, requiring social work engagement in reflective practice and attunement, mentalisation and attending to our subjective feelings. The offer of care activates our own attachment dynamics as caregivers, prompting help-seeking (Heard et al., 2012). This parallel process provides insight through experiential learning of connection, compassion and containment alongside rupture and repair (Levine, 2010; Siegel \& Bryson, 2020).

These principles can be translated to social work research, underscoring reflective practice and reflexive processes as a way of exploring the complexities of our emotional lives and their impact on thinking and research. It suggests that embracing imperfection, predicated on compassion for self and other, may enhance understandings of vulnerability (Brown, 2015). Relational responses to trauma and healing require strengths-based engagement (Levine, 2010). Shifts towards "learning with" LGBTI+ youth highlight holistic approaches which re-centre 
the collective cultural context as integral to wellbeing (Ceatha et al., 2019). It is the use of self within our role and relationships Through HAB that acknowledges our shared experience; a recognition of the self in the other and the interconnectedness of all living beings (Siegel, 2020; Hanrahan, 2011). Theories of interpersonal neurobiology within a framework for cultivating integration provide future directions which incorporate biophilia, premised on recognition of all living beings; social mediation theory, emphasising the sense of connectedness and purpose; alongside attachment theories (Siegal, 2020). It is important, therefore, that social workers and practitioner-researchers engage in observations of HAB with the potential to problematise power relations, foster anti-oppressive practice and, through the use of self, challenge inequity and injustice (Hanrahan, 2011).

\section{Acknowledgements}

Many thanks to my clinical social work supervisor, Deirdre Foran, Director, Group Analytic Practice for creating a reflective space and experiential learning through connection, compassion and containment.

Thanks to Prof. Jim Campbell, Head of School of Social Policy, Social Work and Social Justice and Prof. Kath Brown, School of Geography PhD supervisors with University College Dublin (UCD) for welcoming my inclusion of Bruno as integral to $\mathrm{PhD}$ supervision. Thanks also to Jim for the review, feedback and suggestions which greatly improved this manuscript.

Thank you to Dog's Trust, Ireland. Particular thanks to Sabrina Phelan, Senior Training and Behaviour Advisor.

This article is dedicated to Bruno, who taught me about courage, being big-hearted and the risks worth taking.

Grant information: This work was conducted as part of the SPHeRE Programme under Grant No. SPHeRE/2013/1.
Accepted 10 September 2020

Published 15 December 2020

\section{References}

Baker, K., \& Beagan, B. (2014). Making assumptions, making space: An anthropological critique of cultural competency and its relevance to queer patients. Medical Anthropology Quarterly, 28(4), 578-598. https://doi. org/10.1111/maq.12129

Briggs, S. (2017). Working with troubled adolescents: Observation as a key skill for practitioners. In $\mathrm{H}$. HingleyJones, C. Parkinson, \& L. Allain (Eds.), Observation in health and social care: Applications for learning, research and practice with children and adults (pp. 101-120). Jessica Kingsley Publishers.

Brewer, J. D. (2000). Ethnography. Open University Press.

Brown, B. (2015). Daring greatly: How the courage to be vulnerable transforms the way we live, love, parent, and lead. Penguin.

Ceatha, N. (2016). Mastering wellness: LGBT people's understanding of wellbeing through interest sharing Journal of Research in Nursing, 21(3), 199-209. https://doi.org/10.1177/1744987116642007

Ceatha N., Bustillo M., Tully L., James, O., \& Crowley, D. (2020). What is known about the protective factors that promote LGBTI+ youth wellbeing? A scoping review protocol. HRB Open Research, 3(11). https://doi. org/10.12688/hrbopenres.13018.2

Ceatha, N., Mayock, P., Campbell, J., Noone, C., \& Browne, K. (2019). The power of recognition: A qualitative study of social connectedness and wellbeing through LGBT sporting, creative and social groups in Ireland. International Journal of Environmental Research and Public Health, 16(19), 3636. https://doi.org/10.3390/ ijerph16193636

Cooper, A. (2017). Soft eyes: Observation as research. In H. Hingley-Jones, C. Parkinson, \& L. Allain (Eds), Observation in health and social care: Applications for learning, research and practice with children and adults. Jessica Kingsley Publishers.

Hanrahan, C. (2011). Challenging anthropocentricism in social work through ethics and spirituality: Lessons from studies in human-animal bonds. Journal of Religion \& Spirituality in Social Work: Social Thought, 30(3), 272-293. https://doi.org/10.1080/15426432.20 11.587387

Hayes, A. (2017). Dog tales. Gill Books.

Heard, D., Lake, B., \& McCluskey, U. (2012). Attachment therapy with adolescents and adults: Theory and practice post Bowlby. Karnac Books.

Horowitz, A. (2010). Inside of a dog: What dogs see, smell, and know. Simon and Schuster.

Kvale, S., \& Brinkmann, S. (2009). InterViews: Learning the craft of qualitative research interviewing. Sage Publications.

LaSala, M. C. (2003). When interviewing "family": Maximizing the insider advantage in the qualitative study of lesbians and gay men. Journal of Gay \& Lesbian Social Services, 15(1-2), 15-30. https://doi. org/10.1300/J041v15n01_02 
Levine, P. A. (2010). In an unspoken voice: How the body releases trauma and restores goodness. North Atlantic Books.

Maxwell, J. A. (2009). Designing a qualitative study. In B. Leonard \& D. J. Rog (Eds.), The SAGE Handbook of Applied Social Research Methods. SAGE Publications.

Mertens, D., \& Ginsberg, P. (2008). Deep in ethical waters: Transformative perspectives for qualitative social work research. Qualitative Social Work, 7(4), 484-450. https://doi.org/10.1177/1473325008097142

Phillips, J., \& Hazelby, D. (2018). Canine assistant teachers for student nurses' wellbeing. International Journal of Nursing \& Clinical Practices. https://doi. org/10.15344/2394-4978/2018/279

Russow, L. M. (2002). Ethical implications of the humananimal bond in the laboratory. ILAR Journal, 43(1), 33-37. https://doi.org/10.1093/ilar.43.1.33

Schaub, J., Willis, P., \& Dunk-West, P. (2017). Accounting for self, sex and sexuality in UK social workers' knowledge base: Findings from an exploratory study. The British Journal of Social Work, 47(2), 427-446. https://doi. org/10.1093/bjsw/bcw015

Siegel, D. J., \& Bryson, T. P. (2020). The power of showing up. Scribe Publications.

Siegel, D. J. (2020). The developing mind: How relationships and the brain interact to shape who we are (3rd ed.). Guilford Publications.

Sroufe, A., \& Siegel, D. (2011). The verdict is in. Psychotherapy Networker, 35(2), 35-39. Retrieved from http://www.fullyhuman.co.uk/wp-content/ uploads/2020/05/Soufe_Siegel_Attachment-article-1.pdf

Topál, J., Gácsi, M., Miklósi, Á., Virányi, Z., Kubinyi, E., \& Csányi, V. (2005). Attachment to humans: A comparative study on hand-reared wolves and differently socialized dog puppies. Animal Behaviour, 70(6), 1367-1375. https://doi.org/10.1016/j.anbehav.2005.03.025

Walsh, F. (2009). Human-animal bonds I: The relational significance of companion animals. Family Process, 48(4), 462-480. https://doi.org/10.1111/j.15455300.2009.01296.x 